\title{
The Journey of Adopting Lean Six Sigma - from the Implementation Team's Perspective: A Case Study
}

\author{
Nicoleta Dorina RACOLTA-PAINA ${ }^{1}$ \\ Nicolae Sebastian BUNEA2
}

\begin{abstract}
This paper proposes a case study undertaken within a Romanian company which adopted Lean Six Sigma (LSS) Methodology. The research objectives pursued are the identification of the way in which this process has proceeded, from the implementation team's perspective. The primary data collected while interviewing them target both the positive and the negative aspects, as well as the benefits and the elements that still need improvement as part of the process of LSS implementation. The conclusions of our research indicate some of the positive aspects of Company A's "journey" towards LSS namely: a totally committed management, well trained employees, openness to change from the implementation team and from part of the employees, and also the external consultant's involvement when this was needed. The less positive aspects of the researched process were given by the need to get some of the instruments adjusted (these being specific to the field of production, as the researched team provides products, solutions and electro-technical and mechanical services), the lack of experience regarding LSS from the large majority of the members of the implementation team, and also the long duration of the Analysis stage as part of the D.M.A.I.C. Methodology (Defining, Measurement, Analysis, Implementation, Control) given the large quantity of data. One essential aspect identified is that, in the case of Company A, LSS implementation led to the desired results that is to the change of the organizational culture, to the reducing of operational costs and to performance improvement, and also to improving customer service.
\end{abstract}

KEYWORDS: Lean Six Sigma, qualitative research, case study

JEL CLASSIFICATION: L10, L20, M10, M20, O30

\section{INTRODUCTION}

The interest of contemporary companies to monopolize a wider part of the market and to reach the highest financial performance can materialize only by sustained effort for continuous improvement. For Antony et al. (2017) continuous improvement (CI) synonymous with quality improvement (QI) is an important business strategy for current organizations regardless of the market they perform on, or of their nature and size. Integrating Lean thinking with Six Sigma methodology, which is Lean Six Sigma (LSS) leads to improvements at strategic and operational level (Pepper \& Spedding, 2010). Organization on processes of the companies has become more and more common at present, therefore the improvement of processes is an important component of the efforts of continuous improvement. Contemporary companies often consist of complex processes, situation in which applying the Six Sigma technology has proven to be a real success, as Six Sigma incorporates the philosophy and the instruments specific to Total Quality statistical tools and it involves the top management through the belt rankings (Pugna, et al., 2018). LSS is an intensively studied subject if we are to compare it to the scientific studies which contain specialty literature reviews (Antony et al.,

\footnotetext{
${ }^{1}$ Babeș-Bolyai University, Cluj-Napoca, România, nicoleta.paina@ubbcluj.ro, corresponding author

2 Babeș-Bolyai University, Cluj-Napoca, România, nicolae_bunea23@yahoo.com
} 
2017; Maleyeff et al., 2012; Hill et al., 2018; Maleyeff et al., 2016; Pepper \& Spedding, 2010; Rodgers, et al., 2019). In this context, our interest is to analyze the implementation of LSS methodology within a company, according to the implementation team's members. The case study proposed by us is undertaken within a Romanian company (hereinafter referred to as Company A, due to confidentiality concerns), with Dutch capital, having as primary activity object to supply products, solutions and electro-technical and mechanical services for national and international industrial clients present on the Romanian market. The research question that this study attempts to answer is "How does the implementation process of LSS in Company A take place, according to the members of the implementation team?" We have chosen to learn and to analyze the perception of the members of LLS implementation team within a company with the clear idea that they are the most authorized ones to share their opinions regarding this process of improvement within their company. In order to answer this research question, the main research objectives are: (1) Identifying both the positive and the negative aspects of LSS implementation process and (2) Identifying the benefits as well as the aspects that still need improvement as consequence of adopting LSS.

The study case undertaken is laid on a primary, qualitative research basis, and the methods used are: the direct observation (one of the authors of this study is an employee of Company A) and the interview.

The degree of novelty shared by our research is given by the very case study proposed, the results of the research referring to a specific situation out of which a series of issues of good practice can be drawn out, which can be used by the practitioners involved in the process of LSS implementation, respectively by the aspects that can be the weak link all along this process.

The present work is structured on four parts. The first part of the work contains a short review of the specialty literature regarding the LSS concept, briefly presenting the 4 stages involved by D.M.A.I.C. methodology (which is part of Six Sigma methodology), as well as a series of factors which contribute to the successful implementation of LSS. In the second part of the work, the research methodology which lays at the basis of the study case is presented, and so is the instrument used for collecting the primary data (the interview Guide), along with other relevant aspects related to this process. The main body of the work is comprised of the study case proposed. This part contains a short presentation of Company A (its activity, its way of organizing and namely the context which led to the decision of implementing LSS methodology), as well as the analysis of the primary data collected. The final part encloses the conclusions of the work, which are in accordance with the research objectives of the present work.

\section{LITERATURE REVIEW}

Sreedharan and Raju (2016) review as many as 45 definitions of the LSS concept, their conclusion being that there is no common approach regarding its inclusion in the category of approaches, methodologies, models, philosophies, strategies or systems. However, we are dealing with LSS methodology in this paper, as we believe that this classification is the most suitable as related to the aspects involved by LSS. As it is well known, LSS methodology integrates Lean approach with Six Sigma methodology, each completing the other. Therefore, according to Antony et al. (2017) if Lean approach is not suitable for approaching the complex processes which require in-depth analyses of data and advanced statistic methods, Six Sigma methodology is not justified in case of less complex situations. Munteanu (2017) undertakes an extremely well documented analysis of the Lean, Six Sigma and LSS concepts and he identifies the fact that the success of the processes where LSS is adopted is owed to the 
flexibility that characterizes LSS, given by the possibility of using aspects of Lean approach and of Six Sigma approach depending on the given situation. According to Dragulanescu and Popescu (2015), LSS involves the systematic reduction of the process variability, thus ensuring an improvement of the quality standards of the products and of the services and, at the same time, a consistent reduction of the process production costs (losses). Although LSS occurred within the companies in the field of production (Lean principles have their origins in the field of production and Six Sigma approach was introduced and improved within Motorola company), this is adopted by companies in different fields, such as health services (Hill et al., 2018), the education system (Rodgers et al., 2019), courier services (Dragulanescu \& Popescu, 2015), logistic (Andersson, 2008; Mijajlevsk, 2013; Mitchell \& Kovach, 2016). As, according to Hill et al. (2018) in the great majority of the cases, the implementation of LSS methodologies is focused on the systematic and rigorous enforcement of D.M.A.I.C. approach (which belongs to Six Sigma methodology), we will make a brief presentation as follows below.

D.M.A.I.C. methodology involves going through a set of 5 stages (see Table 1) as part of a process which is named a project, process identified as being suitable for improvement (GoLeanSixSigma, 2012, p. 2). The aim pursued is to reduce as much as possible the sources of variation of the process which cause aspects that need to be improvement.

Table 1. The content of the stages of D.M.A.I.C. methodology

\begin{tabular}{|c|c|c|}
\hline No. & $\begin{array}{l}\text { Name } \\
\text { of stage }\end{array}$ & Content of the stage \\
\hline 1. & Define & $\begin{array}{l}\text { "Project Charter" is created, the perspective being a wide one, with a great accent laid } \\
\text { upon the understanding of the clients' needs, upon the process which is the object of the } \\
\text { project in question. This document will be updated at the end of each stage which comes } \\
\text { next. } \\
\text { It involves the drafting of different documents, such as "Problem Statement", "Goal } \\
\text { Statement", etc. }\end{array}$ \\
\hline 2. & Measure & $\begin{array}{l}\text { The current performance of the process is measured, the data collected being related to } \\
\text { the whole process. Therefore, the starting point of the process is determined and } \\
\text { information is looked for so as to understand the aspects involved in the process. The data } \\
\text { collected are used with a view to identify the causes of the waste involved in the process } \\
\text { in question or the shortcomings which occur as part of this process. }\end{array}$ \\
\hline 3. & Analyze & $\begin{array}{l}\text { The data collected in the previous stage are analyzed, the results obtained being able to } \\
\text { indicate the need for new data. Consequently, not infrequently, this stage is combined } \\
\text { with the previous one. The analysis of the data is a rigorous one, the instruments } \\
\text { employed being the statistical ones, to which other techniques can be added such as } \\
\text { brainstorming with a view to identifying the potential causes of the identified problems. } \\
\text { The transposition of the accumulated information in relevant images allows the team to } \\
\text { easily transmit their conclusions to the management and to other participants involved in } \\
\text { the process. Among the simplest and most used identification instruments of the } \\
\text { problems' cause is the Fishbone Diagram or The } 5 \text { Whys. }\end{array}$ \\
\hline 4. & Improve & $\begin{array}{l}\text { Improvement solutions of the process in question are developed and implemented, the } \\
\text { improvements obtained are measured. }\end{array}$ \\
\hline 5. & Control & $\begin{array}{l}\text { Its aim is to maintain the improvement solutions adopted. } \\
\text { During the control stage, the team is focused on creating a Monitoring Plan in order to } \\
\text { continue to measure the success of the updated process, and on developing an Answering } \\
\text { Plan in case of performance decrease. } \\
\text { It is also regarded as the Continuation stage, as there will always be problems to be } \\
\text { solved and processes to be improved, since there is no perfect process. }\end{array}$ \\
\hline
\end{tabular}

Source: adapted from GoLeanSixSigma (2012) 
Part of the efforts of the contemporary companies of using systematic techniques with a view of improving their activities at organizational level, we will stop briefly at the so called $5 \mathrm{~S}$ technique, whose name comes from five Japanese words, namely Seiri (sort), Seiton (set in order), Seiso (shine), Seiketsu (standardize), and Shitsuke (sustain) (Ghodrati \& Zulkifli, 2013). This technique has a positive impact upon the general performance within industrial companies and it can improve their quality, efficiency and productivity (Ghodrati \& Zulkifli, 2013).

The key factors in successfully implementing LSS identified by Kwak and Anbari (2004) are: management, commitment, organizational involvement, and project governance; project selection, planning, and implementation methodology; Six Sigma project management and control; encouraging and accepting cultural change; continuous education and training. Taking these factors into consideration we can esteem that the implementation process of LSS is an extremely complex one, all those involved (the management of the company, the external consultant, the implementation team, the employees) have a great responsibility and also a real contribution in the process. Dumitrescu and Dumitrache (2011) emphasize that an essential aspect of adopting the LSS methodology by the companies involves "a cultural change at all levels of organization, with a special stress on the top management level." We can find the same idea at Munteanu (2017) who draws the conclusion that the successful implementation of LSS requires an openness to change, including that of the organizational culture, the involvement and the support of the company's management, the connection between LSS and the business strategy.

\section{RESEARCH METHODOLOGY}

In order to conceive this paper, we chose the case study as a research method, which is done within a contemporary company, perfectly fit in the definition given by Dul and Hak (2008), that is "one case (single case study) or a small number of cases (comparative case study) in their real life context are selected, and (b) scores obtained from these case are analyzed in a qualitative manner". The case study undertaken is a descriptive one (Yin, 2009), our research question is a how? type one, with the accent laid on a series of contemporary aspects. As we mentioned in the Introduction, the research question that this study attempts to answer is "How does the implementation process of LSS in Company A take place, according to the members of the implementation team?" The research objectives pursued are: (1) Identifying both the positive and the negative aspects of LSS implementation process and (2) Identifying the benefits as well as the aspects that still need improvement as consequence of adopting LSS.

The study case is undertaken within Company A, a successful company, which operates on the business-to-business market, in the field of providing products, solutions and electrotechnical and mechanical services for national and international industrial clients present on the Romanian market. In order to collect the primary data which, lay at the basis of the study case we made use of the semi-structured interview (which contained 9 questions). Interviews had been taken to the 3 members of the implementation team within Company A with a view to identify their perception regarding the way in which the implementation process of LSS methodology in Company A was taking place. The interviewed people expressed their points of view as members of the LSS methodology implementation team, and also as the company's employees. Since one of the authors of this paper is Company A's employee and also the fourth member of the LSS methodology implementation team, the primary data collection went well and easy. 
An important role was played both by the good cooperation among the colleagues of the firm, as well by the good communication, the employees that we had in view to be interviewed being informed in due time that they were going to be asked to participate in an interview with the purpose of collecting some data so as to undertake a scientific research.

The interview guide used by us was conceived by the two authors of the paper hereby and it contained 9 open questions, formulated in such a way that they would reach the targeted research objectives. The aspects pursued through the questions of this interview were the following:

- Identifying the degree of knowledge about Lean processes when joining the LSS methodology implementation team in Company A (question 3);

- Identifying the perception regarding the proceedings of LSS methodology implementation process (questions $4-6$ );

- Identifying the benefits as well as the more difficult aspects involved by the implementation process of LSS methodology within the company (questions 7 -9).

These questions were completed by 2 others, the first in the Interview Guide, by which it was meant to create a good background in starting the interview, namely "What are the first 3 words that come into your mind when you think of Company A?", respectively "What was the first reaction when you found out that you would be a member of Lean implementation team?".

Given the situation caused by the Covid 19 pandemic, during the period when we collected our data (April - May 2020), our contact with the interviewed people was done via on-line platforms only, by telephone or e-mail. Finally, after many telephone conversations with the people we had in view for our interviews, due to the period with many professional activities, it was decided that the Interview Guide would be sent by e-mail and the answers would be sent by using this means of communication as well. We really appreciated our respondents' openness towards our research initiative, their answers to the questions in our Interview Guide were detailed and fairly explained.

\section{CASE STUDY}

\subsection{About the company}

Company A, which has been functioning since 2008, is a branch of a well-known Dutch company (which was taken over by an important international group in 2010, essential aspect in adopting and introducing the philosophy of quality to the Romanian market). Being a Dutch company which has built itself a reputation in Holland, once with its geographical expansion in Romania, Company A found its place quite easily on the industrial Romanian market, as it already had contracts with clients and suppliers worldwide, which at their turn created and developed their own network.

The main activity field of Company A is to supply electro-technical and mechanical materials, providing a wide variety of products and equipment, from the junction box to the Programmable Logic Controller (PLC) systems. Besides the standard products, Company A differs from other companies competing on the same market, by its products, systems and customized solutions that it provides to its customers.

The main suppliers are: Siemens, Schneider, Abb, Phoenix, Contact, Pilz, Sick, IFM, Pepperl + Fuchs (programmable controllers, industrial switches, grounding and over-voltage protection, inverters, sensors, equipment for electrical cabinets), Lapp Kabel, Helu Kabel 
(cables and conductors, connectors for cables and conductors), Weidmuller, Hummel, Wago, Partex (connectors for cables and conductors, materials for codification and cable installation), Rittal, Eldon (cabinets and electrical cabinets) etc. The market segment targeted by Company $\mathrm{A}$ is made up of producers of original equipment, machine manufacturers, industrial end-users, electrical panels manufacturers, system integrators, and producers in the food industry. The best well-known are: CSI, Comau, Emerson, Heineken, Retrasib, Bosch, Ford, Alewijnse, etc.

At present, Company A has three head establishments in Romania, the main one lies close to the city of Cluj - Napoca (its offices and logistics centre, covering a surface of 2.400 square metres), and the other two can be found in Bucharest and in Timişoara, where only the selling departments operate. It is structured in 7 main departments, namely selling, solutions, logistics, financial, marketing, account management and industrial acquisitions. They, in their turn, are made up of services, such as: Inside Sales, Outside Sales, Industrial Automation, Logistics and Connected Business, Lighting Technology, Store Management, Optimization of Internal Processes, Management of Materials, Acquisitions - Logistics, Accountancy and Human Resources. The main tasks and duties of the employees who work in some of these specialized sub-departments are:

- preparing quotas for customers, providing technical advice regarding the products to the customers, placing orders in the system - in the case of Inside Sales (9 employees);

- exploring new business opportunities from the current and prospective customers, namely approaching them directly - in the case of Outside Sales (4 employees);

- providing technical support for the problems that occur at the customers' automation processes, testing the Hardware and the Software components and also organizing programming courses in Programmable Logic Controller (PLC) - in the case of Industrial Automation (IA) (2 employees);

- offering logistic solutions for improving the processes and reducing the costs (some of the solutions are Vendor Managed Inventory, Spare Parts Optimisation Service, Selfscan, Customer Stock) - in the case of Connected Business (CB) (2 employees);

- accomplishing energy efficiency projects of the industrial lighting installations, which involve the use of performant LED products, facilitating the 3D visualization of the location and the lighting calculation with specialized programmes - Lighting Technology (one employee).

In order to reach the targets, set for 2024, that is a turnover of $50.000 .000 €$ and the automation of the logistic processes in the warehouse, it was decided to get LSS methodology implemented, beginning with January 2019. Company A had a turnover of approximately $10.000 .000 €$ in 2018 (the number of employees is 34 ).

According to one of the authors of the hereby study, Company A's employee, in January 2019, the situation of the company was as follows. All the processes of the company, including the reception and delivery processes of the goods were supported by the SAP system. The reception of the goods was a semi-automatic process; after the employee was taking over the goods checking them on the accompanying notice, by comparing the products with the shipping documents and with the purchase order, following which the products were registered manually in the SAP system and they were placed on the already defined location. The delivery of the goods went, approximately, through the same semi-automatic process. In such a case, the employee selected the client manually in the system and printed a list with the ordered products. After the goods were put together physically, the employee confirmed the collecting of the products in the system and then he sent them to the client. At organizational 
level the situation was rather undesirable, there was no clear procedure for many of the processes in the company, the access in the system was not restricted and for example, the financial department had access to the transactions of the acquisitions department and vice versa; the problems which occurred during the process were solved using the Fire Fighting method, only to see the same problems appearing again in a relatively short time. According to Bohn (2000), the fire-fighting situations are all those situations in which "manager and engineers rush from task to task, not completing one before another interrupts them". The manager, who is of Dutch origin, had a Black Belt certificate in LSS methodology, as a result he tried to provide the employees of Company A knowledge about Lean culture. Still, without a structured approach the results were not the expected ones. The decision regarding the implementation of LSS in Company A had been analyzed for a long time, there was even a negotiation with an external consultant specialized in innovation and in LSS methodology. After concluding a firm contract with this consultant, the steps followed within Company were the following;

- the assigning of an implementation team made up of 4 employees, each of them from a different department, employees who were well acquainted (as consequence of their professional experience and also of their leadership position in their department) with the processes within the company, with the company itself.

- Carrying out a one-day training, in which all the company's employees took part so as to understand the changes the company was about to go through in the next periods of time and so as to comprehend the importance of the cooperation with the implementation team. This training, in terms of Six Sigma is also called the Yellow Belt.

- Carrying out a training for the members of the implementation team with a view to get to know, to understand and to practice the Six Sigma stages (known under the name of D.M.A.I.C.). The training took place over a period of 12 months, each of the five stages being taught every 2 months. This training is the second level of Six Sigma or the Green Belt. As part of the training, the role of the implementation team members is to manage small projects or projects that are focused on one single function. This position is accomplished together with another full-time position.

\subsection{Analysis and interpretation of the collected date}

As we have mentioned before, the primary data which lay at the basis of this study case were collected through direct observation (of one of the authors, who is Company A's employee), and also the interview taken to the LSS implementation team members.

4.2.1. LSS Implementation within Company A - the content of the stages related to D.M.A.I.C. Direct observation, as method of collecting the primary data, had as topic an LSS project implemented within Company A, which pursued the improvement of the processes in relationship with an important client (herein after named Company B, due to confidentiality concerns). The content of the 5 stages of D.M.A.I.C. methodology as part of this LSS project are presented further on:

a) The Definition Stage of D.M.A.I.C. Methodology

In this stage, the implementation team of LSS methodology conceived a graphic of the project, they designed a detailed map of the processes and began to understand the client's needs, namely those of Company B. In order to detect the not so obvious aspects, the LSS team drafted a detailed map of the processes, using Lean specific techniques, such as S.I.P.O.C. diagram (Suppliers, Inputs, Process, Outputs, Customers). 
After the completion of the map of processes, the project team perform a series of interviews with the participants at each process so as to obtain a complete and detailed picture of each step of the process. An essential aspect was the focus on the customer's needs, as the LSS implementation team wished to rightly comprehend Company B and its needs. During the situation under consideration, a process identified as one of the problems and consequently one that needs to be improved was "the process of placing orders by the customer", a situation which often occurred being "the client is not ordering on time".

b) The Measurement stage of D.M.A.I.C. Methodology

The aim of this stage was to gather reference information about the process identified during the definition stage as being subject to improvement. The basic information about this process is used to understand thoroughly what happens during this process, the customer's expectations (in this case, Company B) and what the causes of the identified situation are. Two major aspects were taken into consideration: reducing the time of the process or improving the quality of this process. Along the data gathering process, the team were careful to focus on the process, as well as on what is important for the customer (in this case, Company B).

This stage entailed a series of important aspects:

- Understanding the activities of the process by drafting an updated process map;

- Understanding the point when a risk in the process can occur by achieving an analysis of the way failure appears and of its effects;

- Establishing the process performance as compared to the customer's expectations;

- Assessing the system of data measurement so as to make sure that the data are correct and that no intrinsic variations exist due to the method by which the data are collected.

Furthermore, the implementation team pursued to gather as large as possible amount of data, increasing the accuracy of the results. In order to perform this stage, the team conceived a data collection plan, which contained precise information about who would measure those data, of which part of the process, how long and how it would be measured.

c) The Analysis Stage of D.M.A.I.C. Methodology

This stage started by studying the process identified during the Definition stage and the data collected during the Measurement stage with a view to identify the parameters regarding the potential main causes of the situation "the client is not ordering on time". Following that, the LSS implementation team speculated upon some hypotheses about the reason why the problem exists, so as to point out the causes of the process that needs to be improved, before coming up with any kind of solutions. For the analysis of the data collected in the previous stage, the team used several analysis instruments, especially graphics and diagrams, which provide visual parameters for the problems processing, such as The 5 Whys method or the Cause and Effect Diagram (Fish Bone Diagram). In the case of the analysed situation "the client is not ordering on time", some of the identified causes were: no stock agreements, engineering changes, no lead-time management, buffer times in Supply Chain and so on.

d) The Improvement Stage of D.M.A.I.C. Methodology

In this stage, the LSS implementation team identified solutions, coordinated the processing of the changes, implemented solutions and collected data in order to confirm that there was a measurable improvement of the said process that needed to be improved. The effort of the team was oriented towards producing as many ideas so as to solve the main causes of the problem identified in the Definition Stage. These ideas came from the employees involved in 
the process under analysis, from the members of the LSS implementation team, making use of the comparative assessment or of some classical solutions elaborated in the field of quality management. The result of this stage was the following. (see Table 2)

Table 2. Identified solutions to the causes of "client is not ordering on time"

\begin{tabular}{|l|l|l|}
\hline No. & $\begin{array}{c}\text { Causes of "client is not } \\
\text { ordering on time" }\end{array}$ & \multicolumn{1}{c|}{ Solutions } \\
\hline 1. & No stock agreements & $\begin{array}{l}\text { S1: Stock agreement for items with leadtime (LT) > 4 week } \\
\text { S2: Vendor Managed Inventory (VMI) solution for small parts } \\
\text { S3: Stock agreements with supplier (inclusive triangle agreement) }\end{array}$ \\
\hline 2. & Engineerinf changes & $\begin{array}{l}\text { S1: Speed delivery time (express delivery) } \\
\text { S2: Engineering standardization } \\
\text { S3: Engineering quality validation }\end{array}$ \\
\hline 3. & $\begin{array}{l}\text { No/Poor } \\
\text { management } \quad \text { time-lead }\end{array}$ & $\begin{array}{l}\text { S1: Implement leadtimes } \\
\text { S2: Maintaining leadtimes } \\
\text { S3: Define / setup standard supply chain } \\
\text { S4: Lond lead articles - management }\end{array}$ \\
\hline 4. & Buffer times in Supply Chain & $\begin{array}{l}\text { S1: Eliminate buffer times in Client \& Supplier } \\
\text { S2: Electronic Data Interchange (EDI) ordering with grouping reference } \\
\text { for Alliance projects }\end{array}$ \\
\hline
\end{tabular}

Source: direct observation of one of the authors of this study

e) The Control Stage of D.M.A.I.C. Methodology

In this stage, the LSS implementation team focused upon creating a Monitoring Plan in order to continue to measure the success of the updated process and to establish an Answering Plan in case some performance decrease might be noticed. In this stage, the team updated their documentation: process maps, procedure checklists, etc. According to the things discussed with those who were part of the implementation team, the better the final documentation is, the easier it is for the participants to adopt a new work procedure. One of the most powerful ways of making sure that the other participants in the process follow the new procedure is to create a visual workspace. The implementation team admitted that this stage was not the final point in improving the process, it was just an important stage of D.M.A.I.C. Methodology. With every success, the Company's orientation towards a Lean mindset increases and simultaneously so does the culture of solving problems. For the LSS implementation team, letter $\mathrm{C}$ of the acronym for D.M.A.I.C. Methodology does not mean Control only, but also Continuing, as there will always be problems to be solved and processes to be improved, since no process is perfect.

Going through all the stages presented above led to a series of benefits for Company A, namely: reducing the costs resulting following the order processes accomplished by Company $\mathrm{B}$, improving the internal processes related to receiving orders, an increase in revenue, creating a continuous process and opening new business opportunities in relationship with Company B. To all of these, a series of benefits perceived by Company B can be added, such as: reducing the processing costs of the purchase orders, reducing the space occupied in the deposit and implicitly of the related costs, improving the logistic system, reducing the waiting time, etc.

\subsubsection{Implementing LSS within Company A - according to the perception of the members of the implementation team}

As we have mentioned before, the study case proposed has at its basis the direct observation of LSS implementation process as well as interviews taken to the members of the implementations team (to 3 of the 4 members, as one of the authors of this article is the fourth 
member of the team in question), so as to identify their perception regarding the process carried out in this study. Some information about the three interviewed people is presented further on (see Table 3).

Table 3. Data about the interviewed employees

\begin{tabular}{|l|l|l|l|l|l|l|}
\hline Name & Gender & Age & \multicolumn{1}{|c|}{ Education } & $\begin{array}{c}\text { Type of } \\
\text { specialization }\end{array}$ & Occupied position & $\begin{array}{c}\text { Seniority in the } \\
\text { company }\end{array}$ \\
\hline C.V. & Male & 32 & $\begin{array}{l}\text { University } \\
\text { degree }\end{array}$ & economical & Key account manager & 1 year and 9 months \\
\hline G.M. & Male & 37 & $\begin{array}{l}\text { University } \\
\text { degree }\end{array}$ & technical & $\begin{array}{l}\text { Head of Logistics and } \\
\text { Connected Business }\end{array}$ & $\begin{array}{l}12 \text { years and 3 } \\
\text { months }\end{array}$ \\
\hline V.T. & Male & 39 & $\begin{array}{l}\text { University } \\
\text { degree }\end{array}$ & technical & Head of Sales & $\begin{array}{l}9 \text { years and } 3 \\
\text { months }\end{array}$ \\
\hline
\end{tabular}

Source: Authors

Our observation is that employee G.M. has been in Company A ever since the beginning of its existence, employee V.T. has a great experience in the company while employee C.V. has an experience of less than 2 years, but with experience on the labor market (since he is 32 years old).

Further on, we analyze the answers received to the three interviews taken.

As we have presented above (see point 3. Research Methodology), the first 2 questions had an introductory role, that is to prepare the interlocutor for the deeper questions of the interview. Analyzing the answers received to the first question ("What are the first 3 words that come into your mind when you think of Company A?"), it can be noticed that Company A generates a feeling of trust and of high professionalism in the interviewed employees. Two of the answers contained the word "professionalism", which strengthens the assertion mentioned above. For the first question, two of the three answers were approximately the same, but one answer was rather unusual, that is "Not just distribution". According to one of the authors of this study, Company A's employee, this last answer describes exactly the difference between Company A and its competitors on the market, the company supplies not only materials, but it also provides support and technical solutions to its clients.

In what the first reaction regarding the participation in the LSS methodology implementation team is concerned, the opinions were rather divided. Therefore, if one answer was short and also relevant "Interesting. New Challenge!", the other two answers were longer, and they refer to the opportunity for personal development and for the accumulation of new knowledge. From the point of view of one of the authors of the hereby study, Company A's employee, the opportunity of studying and putting LSS methodology into practice at this level was not to be missed, that is why, when he was informed that he would become part of the company's improvement team, he accepted the news as a challenge, and also as an opportunity to improve his knowledge.

According to the answers received to the question "Until that moment had you ever had any kind of contact with Lean processes? If yes, what was your part in it?", two of the interviewed people had experience regarding the use of some modern management methods, which incorporate Lean thinking in them.

According to the answers received to the questions regarding the implementation process of LSS methodology in Company A, the adjustment of the concept to the processes of the 
company was a rather difficult one, but through the team's adjustment to the situation and through the involvement of the colleagues from the other departments, this challenge started to bring about results. Moreover, of the D.M.A.I.C. stages, the "Analysis" stage was the most difficult to be managed and applied, according to two of the interviewed ones. They claimed that the level of complexity of the "analysis" stage is high, as this process requires operating with statistics tools, the validation of the data being necessary, in equal measure. In what the department colleagues' reaction regarding the implementation of the new system is concerned, all the three interviewed people mentioned that there are two groups, the group of colleagues who are involved and open, and those who cannot change their old habits. According to one of the authors of this study, member of the implementation team, this situation was mentioned as part of the training undertaken (Green Belt), the consultant's advice being to get focused on the people who are involved and who accept the changes, as the others will eventually follow them. It is about a change, therefore the resistance to change occurred in the case of the employees who "cannot change their old habits".

As for the benefits and also for the more difficult aspects brought about by implementing LSS methodology in the company, the responses received are analysed below.

According to the interviewers, the main benefits of Lean philosophy implementation within the company are the change of the organizational culture, reducing the operational costs and improving performance, as well as improving client services. According to one of the authors of the hereby study, Company A's employee, that added value that this methodology brings about is definitely the change of the organizational culture, and also the standardization of the processes and of the procedures. After implementing LSS methodology it could be noticed the way in which the employees' approach of things has changed, as they tried to deal with them beginning from the "root" to the detriment of the "Fire Fighting" method. Even more, we could notice the diminishing of the information chaos, each proposal of improving or dealing with problems is centralized in a document and it is discussed in weekly meetings in which all the department is involved. At this moment, everything takes place according to some clear rules, each department performs only the activities that are entrusted to them according to the company organization model.

In what the negative aspects regarding the Lean system implementation in the analyzed company are concerned, one problem mentioned by the interviewees was the too lengthy time for the system adjustment within the organization, and for the project implementation, therefore the projects progress is very slow. Here comes another negative aspect that is not complying with the methodology and the tendency to get back to the old thinking pattern. One possible explanation for this situation is the employees' lack of experience according to Lean thinking, therefore more careful attention is needed from the project managers in order to identify the people who have not adjusted with the new procedure and also to focus on those who, at least, want a change.

In what the impact of LSS methodology implementation is concerned, according to V.T., Head of Sales in the sales department, and also in the acquisition one, up to this moment, many changes have occurred for the better, moreover, the price level has standardized related to the client profile on the sales, and in the acquisition one, the delivery terms for each product have been introduced in the system for each supplier. The group's mindset change can be added to all of these, the situations are not seen only from the perspective of the department in question. In the case of the Department that deals with the relations between the international clients and Company A, according to C.V., key account manager, at present, a 
project of logistic integration is being developed at the most important of the company's clients, therefore, major changes of the logistic processes have occurred, both for Company A and for the client. According to G.M., Head of Logistics and Connected Business, the greatest positive impact of LSS methodology implementation can be perceived at the warehouse area, the first step being taken by implementing the " $5 \mathrm{~S}$ ' concept, concept which will also be implemented at the office area. The benefits of implementing the "5S" concept at the warehouse area are: the goods can be found much more easily, cleanliness is better maintained, and all the tools and management instruments are sorted and they can be found quite easily.

At company level, according to one of the authors of the hereby study, Company A's employee, after the LSS methodology implementation, the reception process, and also that of products delivery, have greatly improved. At present, the introduction of materials in the system is done automatically, by means of a scanner, and the printing of the products to be delivered is also done automatically. These are examples of palpable results of LSS implementation in the company under consideration.

\section{CONCLUSIONS}

The continuous improvement is a permanent goal for the contemporary companies who wish to be competitive on the market. This goal is a way of achieving the long-term objectives that are targeted as consequence of the adopted strategies. Adopting LSS is one of the means of continuous improvement of the processes, of reducing the costs, and also of increasing performance in relation with the clients. LSS methodology provides all the necessary information and instruments to organizations so that they would optimize the capability of their processes, they would increase their performance, they would reduce variation in the process results and they would reduce operational costs. All these lead to a superior quality of the products and services provided by the companies in question.

The study case proposed by us is undertaken at Company A, where the process of LSS methodology implementation has been taking place beginning with January 2019. Considering the primary data collected by means of observation (by one of the authors, Company A's employee), and also the interviews taken to the members of the LSS methodology implementation team, the following can be concluded.

The positive aspects of adopting LSS methodology at Company A are: a totally committed management, well-trained employees, an openness to change perceived at the implementation team level and at some of the employees', and also the external consultant's involvement whenever that was needed. To all of these, of significant importance is the fact that the Manager of the company, who is of Dutch origin, holds the highest LSS certification, that is the Black Belt.

The less positive aspects of the process under analysis were given by the need to adjustment of some of the instruments (these being specific to the production field of activity, and the company under analysis supplies products, solutions and electro-technical and mechanical services), the lack of experience about LSS of the great majority of the members of the implementation team, and also the long duration of the D.M.A.I.C. (Defining, Measurement, Analysis, Implementation, Control) methodology Analysis stage due to the large amount of data. 
According to the members of the implementation team, adopting LSS has brought about the expected results, namely the change of the organizational culture, reducing the operational costs and performance improvement, as well as the improvement of client service. They claim that the improvements caused by this implementation have a major positive impact upon the organization and also with the clients.

We can notice that the implementation team have managed to get out of the comfort zone and to embrace a new mindset, according to LSS methodology, by succeeding to apply the concept in a relatively short time (1 year and 6 months). The members of the implementation team have acquired the ability to adapt the company processes to LSS methodology, despite the fact that it is a process that has been applied and developed in the field of production, as Company A activates in the field of product supply, solutions and electro-technical and mechanical services. Although in the beginning the implementation team have come across some difficulties in the process of implementing LSS methodology, caused by the lack of experience in this field, the adaptation of the methodology to the logistic process, the presentation of information and the procedure of all the employees involved in the process have gone better and better with the passing of time. Practically, the members of the implementation team have managed to accumulate experience and also to look at the picture as a whole, thus getting to complete pretty many Quick-wins and Kaizen type projects. Practically, all the employees live the new organizational culture, with a strong orientation component towards continuous improvement, aspect mentioned in the studies already published (Pugna, Potra, Negrea \& Mocan, 2018, p. 25).

One last conclusion is that LSS methodology is included in the company's long-term development strategy, in other words, that is believed to be the key towards its success and the instrument by which it will make a difference compared to the market competition.

\section{ACKNOWLEDGEMENTS}

The publication of this article was supported by the 2020 Development Fund of the BabeşBolyai University.

\section{REFERENCES}

Andersson, R. (2008). Lean Six Sigma - a way to make the supply chain resilient and robust. 11th QMOD Conference, (pp. 271-283). Helsingborg: QMOD.

Antony, J., Snee, R., \& Hoerl, R. (2017). Lean Six Sigma: yesterday, today, and tomorrow. International Journal of Quality \& Reliability Management, 34(7), 1073-1093.

Bohn, R. (2000, July-August). Stop Fighting Fires. Harvard Business Review, Retrieved from https://hbr.org/2000/07/stop-fighting-fires

Dragulanescu, I., \& Popescu, D. (2015). Quality and competitiveness: a lean six sigma approach. Amfiteatru Economic, 17(9), 810-825.

Dul, J., \& Hak, T. (2008). Aims and overview of this book. In J. Dul, \& T. Hak, Case Study Methodology in Business Research, 3-29, Oxford: Elsevier Ltd.

Dumitrescu, C., \& Dumitrache, M. (2011). The Impact of Lean Six Sigma on the Overall Results of Companies. Economia. Seria Management, 14(2), 535-544.

Ghodrati, A., \& Zulkifli, N. (2013). The Impact of 5S Implementation on Industrial Organizations' Performance. International Journal of Business and Management, 2(3), 43-49. 
GoLeanSixSigma. (2012). DMAIC: The 5 Phases of Lean Six Sigma, Retrieved August 25, 2020, from https://goleansixsigma.com/wp-content/uploads/2012/02/DMAIC-The-5Phases-of-Lean-Six-Sigma-www.GoLeanSixSigma.com_.pdf

Hill, J., Thomas, A., Mason-Jones, R., \& El-Kateb, S. (2018). The implementation of a Lean Six Sigma framework to enhance operational performance in an MRO facility. Production \& Manufacturing Research, 6(1), 26-48.

Kwak, Y. H., \& Anbari, F. (2004). Benefits, obstacles, and future of six sigma approach. Technovation, $X X, 1-14$.

Maleyeff, J., Arnheiter, E. A., \& Venkateswaran, V. (2012). The continuing evolution. The TQM Journal, 24(6), 542-555.

Mijajlevsk, A. (2013). The Six Sigma DMAIC Methodology in Logistics. 1st Logistics International Conference (pp. 227-232). Belgrad: LOGIC.

Mitchell, E., \& Kovach, J. V. (2016). Improving supply chain information sharing using Design for Six Sigma. European Research on Management and Business Economics, 22, 147-154.

Munteanu, A. (2017). Comparative Analysis between Lean, Six Sigma and Lean Six Sigma Concepts. Management and Economics Review, 2(1), 78-89.

Pepper, M., \& Spedding, T. (2010). The evolution of lean Six Sigma. International Journal of Quality \&, 27(2), 138-155.

Pugna, A., Potra, S., Negrea, R., \& Mocan, M. (2018). DMAIC Six Sigma for Complex Processes Improvement. In S. Kadry, Understanding Six Sigma: Concepts, Applications and Challenges (pp. 25-63). Nova: Nova.

Rodgers, B., Antony, J., \& Gupta, S. (2019). A critical perspective on the changing patterns of Lean Six Sigma research. International Journal of Productivity and Performance Management, 68(1), 248-258.

Sreedharan, R. V., \& Raju, R. (2016). A systematic literature review of Lean Six Sigma. International Journal of Lean Six Sigma, 7(4), 430-466.

Yin, R. K. (2009). Case Study research. Design and Methods. Fourth Edition. Sage Publications. 